\title{
The Coral Proto - Free Ocean Carbon Enrichment System (CP-FOCE): Engineering and Development
}

\author{
Malcolm Marker ${ }^{1}$, D. I. Kline ${ }^{2}$, W. J. Kirkwood ${ }^{3}$, K. Headley ${ }^{3}$, P. G. Brewer ${ }^{3}$, E. T. Peltzer ${ }^{3}$, T. Miard ${ }^{2}$, A. Chai ${ }^{2}$, M. James $^{1}$, K. Schneider $^{4}$, J. $^{2}$ \\ Silverman $^{5}$, K. Caldeira ${ }^{4}$, J. R. Koseff ${ }^{6}$, S. Monismith ${ }^{6}$, B. Opdyke ${ }^{7}$, R. Dunbar ${ }^{6}$, R. White ${ }^{1}$, S. Dove ${ }^{2}$, O. Hoegh-Guldberg ${ }^{2}$
}

1. University of Queensland, Brisbane, Australia

2. Global Change Institute, University of Queensland, Brisbane, Australia

3. Monterey Bay Aquarium Research Institute, Monterey, California, USA

4. Carnegie Institution, Department of Global Ecology, Stanford, CA, USA

5. Israel Oceanographic \& Limnological Research Ltd., Haifa, Israel

6. Woods Institute for the Environment, Stanford University, Stanford, California, USA

7. Australian National University, Canberra, Australia

\begin{abstract}
Ocean acidification is driven by increasing atmospheric $\mathrm{CO}_{2}$ and represents a key threat to the Great Barrier Reef (GBR) and other coral reefs globally. Previous investigations have depended on studies in aquaria that are compromised by reduced ecological complexity and buffering capacity, and problems associated with containment. These aquaria studies also include artifacts such as artificial flow, light, temperature, and water quality conditions. In order to avoid these issues a new technology was needed for in situ science. This need was the driver behind development of the Free Ocean Carbon Enrichment (FOCE) approach. FOCE is similar in approach to the Free Air Carbon Enrichment (FACE) experiments pursued on land for almost two decades. FOCE as a systems concept was developed at the Monterey Bay Aquarium Research Institute (MBARI) to perform controlled in situ studies on the effects of increased carbon dioxide on ocean environments. FOCE systems inject carbon dioxide enriched water into the desired control volume to lower the environmental $\mathrm{pH}$ to a specified value.
\end{abstract}

The challenge of maintaining reef conditions while manipulating the carbonate chemistry further advanced the FOCE concept. A shallow water reef version of FOCE was needed to perform this research at the University of Queensland. Working with MBARI the University of Queensland developed the Coral Proto - Free Ocean Carbon Dioxide Enrichment (CP - FOCE) system. Although the CPFOCE does not differ conceptually from the original FOCE it is different in a couple of respects. First, it requires that a region of the coral flat be semi-enclosed in the chamber section of CP-FOCE. This allows the required amount of $\mathrm{CO}_{2}$ to be optimised. Second, by closing the enclosure off fully for a short time, the oxygen levels and carbonate chemistry can be accurately measured to determine net production/respiration as well as the calcification/dissolution rates of the organisms living within the chamber.

In this paper we present the engineering details of the CPFOCE system design. This paper details the unique engineering design and challenges of the CP-FOCE system The paper briefly outlines the chemical and biological requirements that provided the technical specifications for CP-FOCE to successfully study the impacts of the changing water chemistry on the physiology of calcareous reef organisms including corals and calcareous algae. We have also a brief outline of the methods used to perform measurements of calcification and dissolution rates. Additionally, we include discussion on production and respiration rates in CP-FOCE systems when maintained at ambient and two different increased $\mathrm{pCO}_{2}$ scenarios. We present technical results of this first deployment and address future plans for modifications and deployments of CP-FOCE. Forthcoming peer reviewed papers will describe the biological, chemical, and geochemical responses.

\section{INTRODUCTION}

The partial pressure of $\mathrm{CO}_{2}$ in the atmosphere is currently increasing at the rate of around 2 parts per million (ppm) per year. The current level of $\mathrm{CO}_{2}(387 \mathrm{ppm})$ is the highest level seen in the last 740,000 years and the rate of change is $2-3$ orders of magnitude greater than any seen in that time [1]. There is no longer any doubt the earth's climate system is changing as a result [2]. Global atmospheric temperatures are now approximately $0.7^{\circ} \mathrm{C}$ higher than 100 years ago and projections suggest additional increases of 2-6 ${ }^{\circ} \mathrm{C}$ by 2100 in response to increases of atmospheric $\mathrm{CO}_{2}$ to levels of 450-800 ppm [3]. Many other aspects of the climate system (e.g. hydrological cycle, storm intensity) are also changing as global temperatures increase, with implications for a broad range of natural and manmade systems $[4,5]$. One of the most dramatic examples of this has been widespread coral bleaching events which began to occur after 1979, resulting in the mass mortality of corals in Australia's Great Barrier Reef and other reef ecosystems around the globe $[1,5,6]$. Serious changes are already underway but the implications for natural ecosystems as well as socio-economic systems are not understood [5]. Moreover, the general populace and policy makers of the world have been almost solely focused on the atmosphere and cryosphere. It is only a recently that 
scientists have been able to get the message out that the Earth's oceans are a key participant in this issue.

Approximately $30 \%$ of the $\mathrm{CO}_{2}$ that enters the atmosphere is absorbed by the ocean, where it reacts with carbonate ion resulting in a lowering of $\mathrm{pH}$ [10] this phenomenon is known as ocean acidification. These reduced concentrations of carbonate have the potential to affect a wide range of marine ecosystems $[11,12,13,14]$.

Carbonate ion concentrations plotted together with global temperatures reveal that the conditions that marine organisms are experiencing today are substantially different from any that they have experienced over at least the last 740,000 years $[1,2]$. In the case of corals, there appears to be a significant carbonate threshold that occurs when atmospheric $\mathrm{CO}_{2}$ rises above $450 \mathrm{ppm}$ (carbonate ion concentrations $\sim 200$ umol. $\mathrm{kg}^{-1}$ ). Reef-building corals appear unable to maintain reef integrity beyond this point. Increases in $\mathrm{CO}_{2}$ above $450 \mathrm{ppm}$ consequently have potentially serious implications for coral reef ecosystems [3].

$\mathrm{CO}_{2}$-induced reductions in carbonate ion concentration are sufficient to slow the calcification rate of many marine organisms $[15,16]$. There is now abundant evidence that ocean acidification is beginning to affect marine life [7][9][10], with a number of studies on corals revealing that calcification decreases linearly with decreasing carbonate ion concentration in seawater. This decrease has been detected in long-lived corals of the genus Porites on the Great Barrier Reef (i.e. 20\% decrease in calcification over the past 20 years; [19]). Studies on crustose coralline algae have also revealed a high sensitivity to ocean acidification [20,21]. This is likely to have significant synergistic impacts on the resilience of coral reefs to other disturbances arising from global warming (i.e. bleaching events), local human stressors (e.g. declining water quality, over-fishing of herbivores), and increased storm frequency.

The CP- FOCE experimental platform provides an ideal design to study the complex, interactive impacts of ocean acidification on a coral reef ecosystem. It has been designed to produce the experimental $\mathrm{pH}$ conditions predicted for future reefs within discrete limits in situ while allowing for multidisciplinary experiments on the coral reef community with tightly monitored environmental conditions within the cabled observatory. The Heron Island CP-FOCE is the first of its kind, making the Heron Island climate change observatory a pioneering site for ocean acidification research.

\section{CONCEPT DEVELOPMENT}

Over a number of years the Monterey Bay Aquarium Research Institute (MBARI) has performed a series of small scale $\mathrm{CO}_{2}$ experiments [27]. These early experiments quickly revealed various problems associated with uncontrolled $\mathrm{pH}$ excursions driven by the tidal cycles. The issues demonstrated that longer term observations would require much more stability and control over environmental manipulations such as $\mathrm{pH}$ and total dissolved $\mathrm{CO}_{2}$. The experiments are analogous to those carried out on land with routine large scale $\mathrm{CO}_{2}$ enrichments, those are the Free Air $\mathrm{CO}_{2}$ Enrichment Experiments (FACE experiments, Fig 1, $[21,22])$. In the FACE experiments, towers release $\mathrm{CO}_{2}$ into the local air at controlled rates to bathe the local vegetation in levels of $\mathrm{CO}_{2}$ that simulate the conditions predicted for the later part of this century.

The FACE technology has been modified by MBARI scientists for use in the marine environment and termed the Free Ocean $\mathrm{CO}_{2}$ Enrichments Experiments (FOCE experiments, Fig 2, [21,22]). MBARI have used the FOCE systems successfully in marine acidification experiments but this will be the first application on a coral reef and likely the start of a global network of coral reef FOCE experiments.

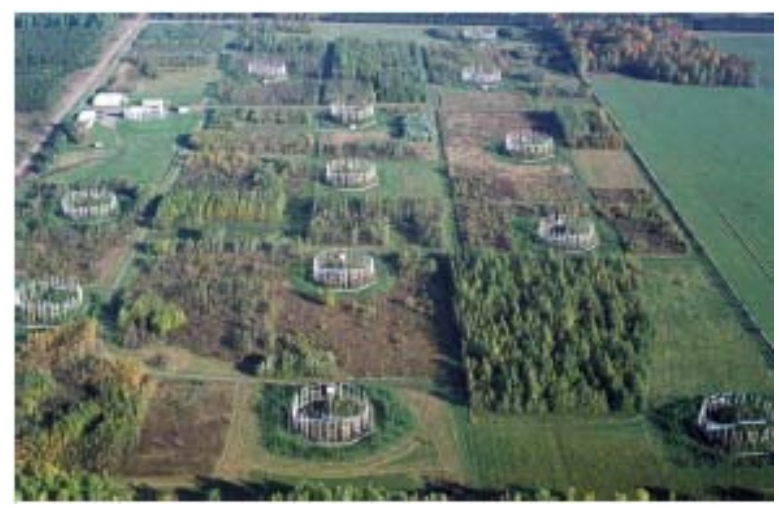

Figure 1: Photograph of a FACE experiment in Wisconsin

The FOCE system concept is based upon the multi-year efforts and success of the FACE systems. The specifications were modified to address the environmental differences of being in the ocean such as being in an incompressible fluid, tidal currents, chemistry, mixing dynamics and closed loop control variables. Science required the monitoring of $\mathrm{pH}$ as the primary variable for control. Using this approach presented several challenges since the rate of the $\mathrm{pH}$ controlling reactions are dependent on the 
temperature of the seawater and on the initial $\mathrm{pH}$ condition [26]. In the interest of quick development the prototype limited the initial operational current range from 10 to 30 $\mathrm{cm} / \mathrm{sec}$. This allowed the demonstration of the FOCE concept and that is scalable without substantial engineering investment.

\section{FOCE DEVELOPEMNT BACKGROUND}

The FOCE prototype design is constructed from a series of distinct subsystems; FOCE frame, directional control valve, mixers and plumbing, system controls, $\mathrm{pH}$ instrumentation, and environmental instrumentation. Each subsection was designed and built to be as simple as possible while strict interface control assured quick integration later. The benefit of these efforts was to demonstrate that other than a few key components requiring technical expertise the system can be designed, constructed, tested, deployed and operated by a diverse set of science and technology individuals. FOCE must be configurable to accommodate a variety of interested science community users and must therefore be easily transferable. This unit was used for component testing only - valves, electrodes, flow sensing, and control software [27]. It served that purpose well and it lead to the next generation systems where provision was made for the significant time lags in achieving $\mathrm{pH}$ equilibrium after injection of a $\mathrm{CO} 2$ rich fluid. Such systems can now provide very good approximations to the emerging high $\mathrm{CO} 2$ ocean conditions.

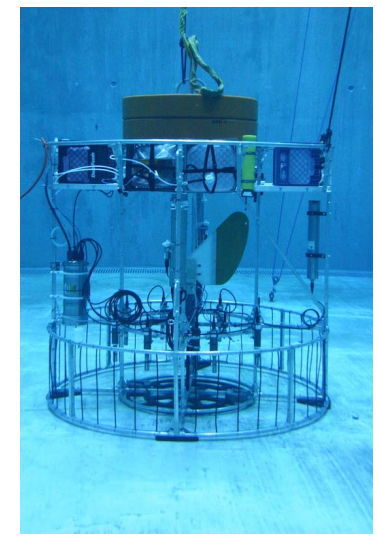

Figure 2: Prototype FOCE System used for component testing and controls concept experimentation

\section{A. Directional Control of pH Adjustment Media}

Prototype testing implemented passive control for upstream release of the $\mathrm{HCl}$ and was selected to keep the electronics and equipment simple for rapid prototyping. This was obviously not suitable for the long term as the dynamics of the anticipated environments science is interested in will vary beyond the limited testing scope initially undertaken. To address this MBARI engineering upgraded the system design to incorporate $\mathrm{CO}_{2}$ control using $\mathrm{pH}$ and to "smooth" $\mathrm{pH}$ variations and timing using velocity as an additional control loop (Figure 3).

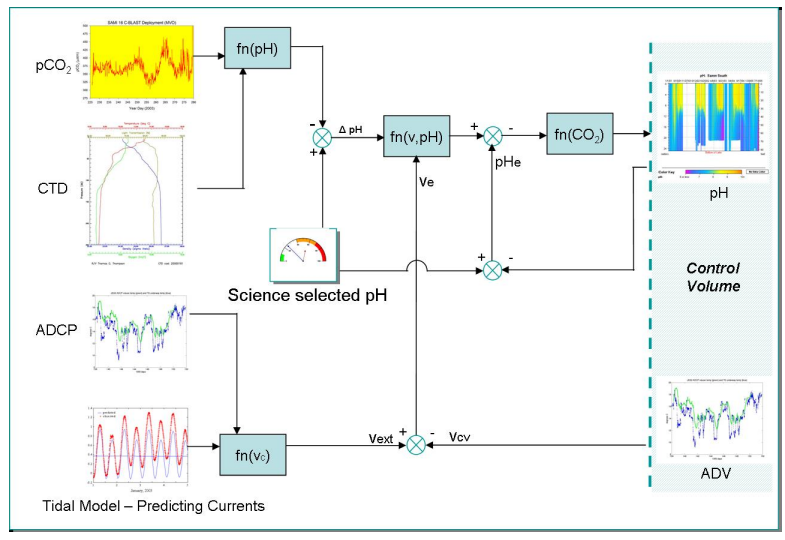

Figure 3: Simple Diagram of the FOCE Control System

\section{B. FOCE as an Observatory Cabled System}

The first phase of a cabled FOCE system was demonstrated in late December of 2008 on the Monterey Accelerated Research Site (MARS). The MARS cable is approximately 52-km (32-mile) out in the Monterey Bay with the bottom node at 900 meters depth. The cabled FOCE design has a science specified area approximately $1 \mathrm{~m} \times 1 \mathrm{~m} \mathrm{x}$ $.5 \mathrm{~m}$ in height for controlled $\mathrm{pH}$ experiments. The FOCE framework is made up of 3 sections. The center section, which is the active FOCE system in actuality, carries all of the instrumentation and core elements that make up the FOCE system. The other two sections are identical "wings" that provide the delay loop paths on each end of the center section. The delay sections fold up as wings for deployment and recovery, shown in Figure 4. The design also incorporates an open underside allowing for the normal transit of bottom sediments and the associated nutrients.

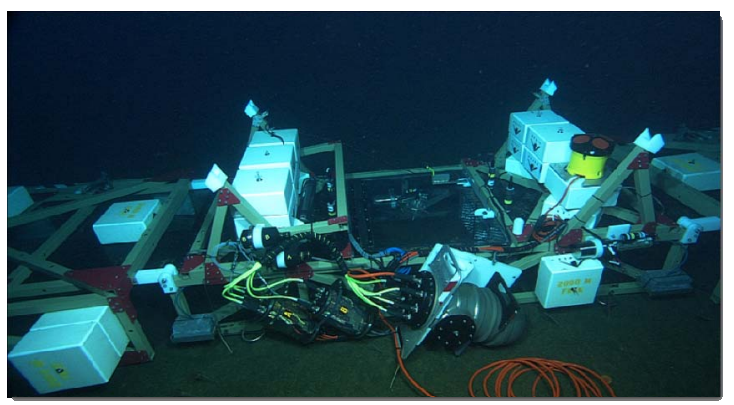

Figure 4: The cabled FOCE system deployed on MARS at 900 meters in the Monterey Bay Submarine Canyon 
The frame is constructed from square fiberglass tubing and stainless steel hardware. The containment is achieved with clear polycarbonate. The balance of the system is typical construction for deep water applications with pressure compensated motors, deep rated cables and connectors, and standard oceanographic instruments. Because of the cold temperatures the system control loop is tuned to create delay loops based on the Zeebe and WolfGladrow model [26]. The system was able to demonstrate flow control and the relationship of the time delay loop to enriched $\mathrm{CO}_{2}$ inputs; one set of such tests is shown in Figure 5.

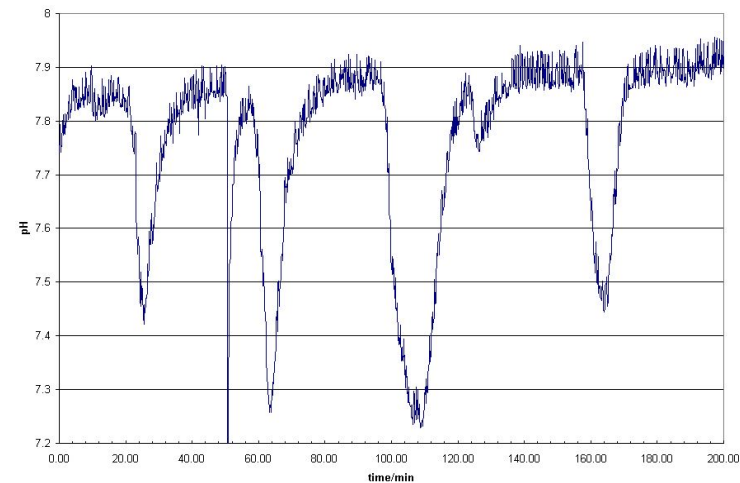

Figure 5: Velocity control of $\mathrm{pH}$ adjusted water showing the interplay of flow and $\mathrm{pH}$ as a control example. The noise at higher $\mathrm{pH}$ is result of swirling from un-damped currents of the surrounding environment.

\section{CP-FOCE DEVELOPMENT}

Heron Island Marine Station was selected as the test site for the CP_FOCE primarily due to the proximity of the lab and ability to literally walk to the test site on the reef. The issue with this site however is the currents are abnormally strong due to a manmade harbor entry that causes a flushing effect. The belief being that by creating a version of the FOCE system that performs as desired at Heron, the system could be applied to diverse reef environments. The CP-FOCE tackles this environmental challenge and represents the first in-situ measurements of $\mathrm{CO}_{2}$ enrichment on a coral reef under ambient conditions.

In general reef currents substantially increase the amount of $\mathrm{CO}_{2}$ required if not addressed by restricting the flow. In turn, the high $\mathrm{CO}_{2}$ necessary increases the pumping power required for dosing the test area to the desired $\mathrm{pH}$. This problem is exacerbated by the response time required for the $\mathrm{CO}_{2}$ to modify the carbonate chemistry and reduce the $\mathrm{pH}$ to the desired experimental level. The approach is to inject $\mathrm{CO}_{2}$ saturated seawater as needed for the experimental chamber setting and allowing the required reaction time to properly equilibrate to the new $\mathrm{pH}$ value. This seawater then flows through the chamber and when exhausted from the opposite side it is transported away from the experimental area leaving no traceable signal after approximately 1 meter. To reduce the water flow, the chamber was designed to be practical with $\mathrm{CO}_{2}$ use thereby enabling the deployment in the challenging coral reef flat environment. The design of the flow control is the main adjustment in the design between the MBARI FOCE and the CP-FOCE. The CP-FOCE, while controlling pH levels, keeps the same FOCE characteristics that minimize the impact on the marine organisms being studied by allowing for normal environmental and marine interactions.

These changes are driven predominantly by the differences in prevailing environmental currents and local temperatures. For example, tidal currents typically differ by one or two orders of magnitude: maximum tidal currents on the coral reef flats can exceed $5 \mathrm{~m} / \mathrm{s}$, compared to $0.5 \mathrm{~m} / \mathrm{s}$ the deep oceans. These higher currents substantially increase the amount of $\mathrm{CO}_{2}$ and energy required to set and maintain a desired $\mathrm{pH}$ offset for a given volume unless carefully managed. The temperature in a coral reef is however is substantially higher than the deep sea FOCE and this reduces the amount of time required to complete a $\mathrm{CO}_{2}$ reaction. This allows the system to be substantially smaller which reduces complexity. Also, in the coral reef environment, $\mathrm{CO}_{2}$ is pulled from the water within the sampling chamber during daylight hours, particularly at low tide, as samples undergo photosynthesis. Another large consideration is the imbalance with atmospheric $\mathrm{CO}_{2}$. The acidified water is in an atmosphere that will not be seen for 100 years, therefore the $\mathrm{CO}_{2}$ chemistry of the system is constantly attempting equilibrium by off-gassing. This further increases need for careful management and the amount of $\mathrm{CO}_{2}$-enriched seawater required to maintain a desired $\mathrm{pH}$ offset.

\section{A. Adapting FOCE to Coral Reefs}

A CP-FOCE chamber consists of three sections; a flow conditioner located at each end and the centre experimental chamber. The chambers are secured on the reef so that their longitudinal axis is aligned with the prevailing currents. The chamber is open at both ends to allow flow from either side of the chamber. The CP-FOCE controls the flow using restrictors located in the flow conditioners. Depending on the flow direction, $\mathrm{CO}_{2}$ enriched water is injected into the upstream flow conditioner relative to the working chamber. The flow 
conditioners provide passive mixing of the enriched seawater and the ambient seawater, to produce well-mixed seawater. It is important to note that mixing will not provide proper $\mathrm{pH}$ water. The critically important aspect of this portion of the system is to provide the proper time delay that ensures a complete $\mathrm{CO}_{2}$ reaction. As stated previously this is a function of temperature and initial $\mathrm{pH}$ since this is a chemically driven system [26].

At the higher temperatures and lower pressure near the coral reef, the residence time required for $\mathrm{CO}_{2}$ to react fully with seawater to lower the $\mathrm{pH}$ is short compared with the deep sea case. However, the higher currents, along with operational concerns, require that the seawater be enriched (i.e., with $\mathrm{CO}_{2}$ ) to the desired $\mathrm{pH}$ value in a large holding tank on shore. It is subsequently delivered to the FOCE chambers by a system of peristaltic pumps.

Several factors, including remote location, proximity of the deployment site to the shoreline, and onsite fabrication resources called for a system that can be deployed and serviced manually using minimal equipment and personnel. These requirements led the team to design a smaller chamber for CP-FOCE that could be transported and installed by hand.

The combination of high currents and the relatively small chamber size led to the development of a system of flow restrictors to limit the current inside the sample chamber and conditioners to ensure adequate distribution and mixing of ambient and enriched seawater.

Apart from changing the $\mathrm{pH}$ in the FOCE environment, both MBARI and CP-FOCE implementations are designed to minimize disturbance of other environmental parameters.

\section{B. CP-FOCE Experimental Chamber}

The experimental chamber is a $0.25 \mathrm{~m} \times 0.25 \mathrm{~m} \times$ $1.0 \mathrm{~m}$ polycarbonate box with an open bottom to provide biological interaction with the benthos (Fig. 6). The polycarbonate used is UV-transparent to provide the best possible transmittance of light into the chamber over the PAR and UV spectrum. The $10 \mathrm{~mm}$ polycarbonate wall thickness has approximately a $20 \%$ loss of intensity across the whole PAR range up to $400 \mathrm{~nm}$ (near ultraviolet), which is a level that already saturates photos systems and thus should not have a large impact on production rates. A flat
$10 \mathrm{~cm}$ wide rubber skirt is connected to the $10 \mathrm{~cm}$ polycarbonate base that are attached with sand anchors to the sandy bottom, and the skirts are buried with a small amount of sand. The rubber skirting on the polycarbonate base provides better sealing between the sample chamber and the outside seawater. This provides an effective seal along the entire length of the chamber and inhibits sand scouring. The present design is intended for deployment on sandy substrate only.

The chamber is broken up into three sections, two outer ends and one mid-section. The outer sections hold the biological test samples while the mid section is left empty to enable accurate water velocity measurements. The experimental sections are sealed using a guillotine style sliding door on each side for respirometry and calcification measurements. All three sections are $30 \mathrm{~cm}$ long, using 1/4" diameter polycarbonate tube with a Leur lock sampling valve that can be used for sampling the sea water from the chambers with syringes.

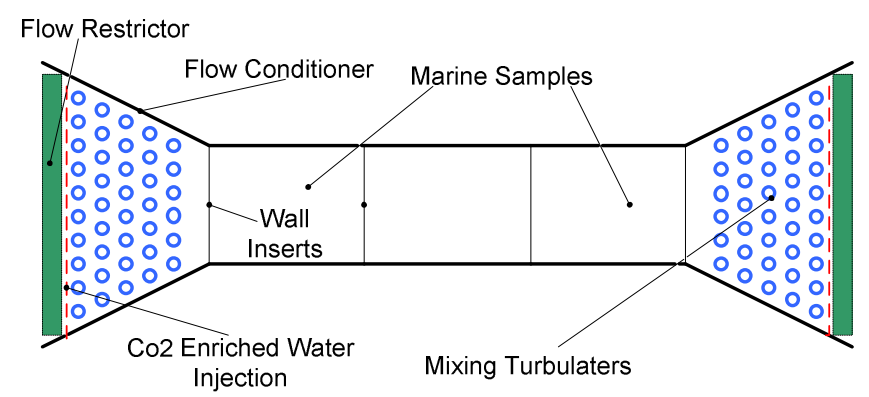

Figure 6: CP-FOCE chamber and flow conditioners

\section{Hydrodynamic Flow}

The design of the flow conditioners provide for flow control, dosing, mixing and conditioning of larger scale turbulence while allowing mobile marine organisms that normally interact with the corals access to the CP-FOCE chamber. In the December 2009 deployment flow was passively controlled by manually adjustable louvers. This provided a good range of flow at which the dosing rate could be maintained. The dosing rates could not, however, be maintained for flows with a $0.25 \mathrm{~m} / \mathrm{s}$ velocity through the chambers, and $\mathrm{pH}$ control becomes near impractical at low flow rate during slack tide. To improve the system active flow control is being investigated to improve the operating range of the CP-FOCE chambers.

The $\mathrm{CO}_{2}$ enriched water is injected into the flow conditioners by perforated tubing distributed behind the 
flow restrictors. An array of vertical tubes both disrupt any large scale vortices shed from the inlet and provide smaller scale turbulence for mixing the enriched $\mathrm{CO}_{2}$ sea water with the ambient seawater. To help inhibit the growth of algae the flow conditioners are opaque. The flow conditioners also serve as a barrier to sand scouring within the chambers as the sand drops out of the low velocity water and accumulates in the flow conditioners. This has an added benefit of protecting the experimental organisms from being buried in sand or being damaged by scouring.

The chambers are secured on the reef so that their longitudinal axis is aligned along the prevailing current direction. The chamber is semi open at both ends to allow flow from either end of the chambers. Control of the flow is provided by the forward and rear flow conditioners. Depending on the flow direction $\mathrm{CO}_{2}$ enriched water is dosed into one of the flow conditioners up stream of the working chamber. The flow conditioners also provide passive mixing of the enriched seawater and the ambient sea water, to produce a well-mixed $\mathrm{pH}$ enriched seawater of the appropriate $\mathrm{pH}$ value.

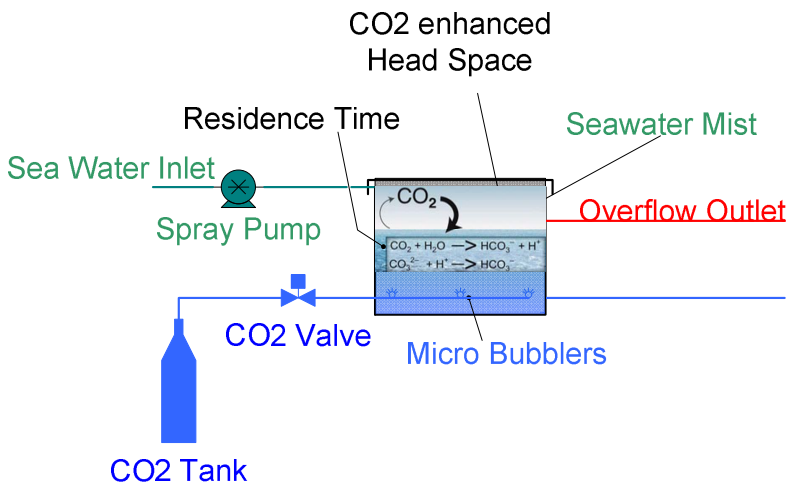

Figure 7: Generation of low $\mathrm{pH}$ seawater in a holding tank to serve as the source fluid.

\section{Low $p H$ water generation}

To decrease the $\mathrm{pH}$ in the CP-FOCE chambers, a supply of low $\mathrm{pH}$ water was generated on the shore to mix in with environmental sea water in the flow conditioners. Sea water from the Heron Island Research Station (HIRS) aquarium system was pumped into a $1000 \mathrm{~L}$ holding tank through a misting system. $\mathrm{CO}_{2}$ is bubbled through the water with a ring of micro bubblers that extend across the bottom of the storage tank and increase the surface area of the $\mathrm{CO}_{2}$ gas to increase the rate it is dissolved into the water. $\mathrm{CO}_{2}$ gas that that is not dissolved is kept in a head space with sea water being misted through it (Fig 7). The partition (relative concentrations) of the dissolved inorganic carbon species i.e. carbonic acid $\left(\mathrm{H}_{2} \mathrm{CO}_{3}\right)$, bicarbonate $\left(\mathrm{HCO}_{3}{ }^{-}\right)$and carbonate $\left(\mathrm{CO}_{3}{ }^{2-}\right)$ is depending on the $\mathrm{pH}$, pressure, salinity and the temperature of the sea water. When a high concentration of $\mathrm{CO}_{2}$ is dissolved in the water, higher quantities of bicarbonate ions are formed that release hydrogen ions during the reaction. It is the hydrogen ions which decrease the $\mathrm{pH}$ in the tank.

The $\mathrm{CO} 2$ flow rate is maintained to keep a positive pressure of pure $\mathrm{CO}_{2}$ in the tank, slightly higher than atmospheric pressure. The time it take for the $\mathrm{CO} 2$ gas to dissolve and produce the hydrogen ions, is the residence time. At pumping rates of up to 51 of seawater from the holding tank per minute there is an minimum turn over time of 200 minutes. The residence time is considerably less than this. In the Dec 2009 deployments, the $\mathrm{pH}$ enriched water was maintained at a $\mathrm{pH}$ of about 5.9.

\section{E. Instrumentation}

Each CP-FOCE chamber includes an instrumentation suite to provide scientific data as well as to maintain control of the $\mathrm{pH}$ value within the chamber. A Seabird SBE-19plus CTD provides salinity data and temperature measurements of sufficient accuracy for $\mathrm{pH}$ calculations. The CTD is also equipped with an analog light (PAR) sensor that is placed within each of the chambers (Fig 8).

MBARI digital $\mathrm{pH}$ sensors provide direct $\mathrm{pH}$ measurement values inside the FOCE chamber. With proper calibration and accurate temperature measurements, these sensors provide $\mathrm{pH}$ measurement with accuracies of approximately \pm 1 milli-pH unit. In the coral reef environment, biofouling required that these be recalibrated every 48-72 hours. The $\mathrm{pH}$ sensors were calibrate to the sea water $\mathrm{pH}$ scale. The $\mathrm{pH}$ sensor outputs is a digitized voltage value, which may be converted to a $\mathrm{pH}$ value using the measured temperature according to the Nernst equation.

Nortek, Vectrino Doppler current meter provides the magnitude and direction of current flow inside the chamber; this current measurement is used by the control system to set the injection location for low-pH seawater.

In addition to the sensors inside each chamber, an additional CTD, $\mathrm{pH}$ sensor along with a Nortek Vector 3D current meter read the ambient environmental conditions outside the chamber. 




Figure 8: Photograph of the CP-FOCE chambers deployed on the Heron Island reef flat. The Sea Bird CTD is seen in front of the chamber and the mixing pumps and light sensor are visible inside the chamber.

$\mathrm{CO}_{2}$ enriched water is pumped (assisted by gravity) from the holding tanks to the chambers using a pair of $1.51 / \mathrm{min}$ peristaltic pumps for each chamber. The water is directed to either end of the chamber, so that the low-pH water may be injected so that it is carried into the chamber with the prevailing tidal current. The peristaltic pump that is turned on is selected using the current measurement and its speed is modulated by a control loop closed about the $\mathrm{pH}$ value. The sample sections of each chamber use inexpensive bilge pumps to circulate water when the chambers are closed.

\section{F. System Overview}

The CP-FOCE control and data acquisition system is designed to be modular with each chamber having a separate controller that can us the $\mathrm{pH}$ values from the environmental and CP-FOCE chamber sensor. One of the design concepts is to be able to deploy variations of the system to different reef location on the Great Barrier Reef and around the world. All measured variables are available to each other control system on a local network to allow sharing of the environmental data and for future developments. Each controller then only needs power and communications to operate individually.

The control, communication and power pods, batteries and solar generation are deployed on a buoy. A wind generator is mounted on a pole and surrounded by an plastic shroud, required by local permitting regulations to protect birds from collision with the turbine blades.

There is provision for external power via a DC link to shore if required. During the 5 days of testing and deployment in
Dec 2009 the system was adequately powered by wind (400w peak) and solar (80w peak) using 400Ahr deep cycle batteries. The System is designed to run with or without communications to the shore. With communications, full real time sensor and experiment control is available.

\section{G. Electronics}

The control pods data acquisition and control was developed on the National Instruments Compact RIO PAC. Although other embedded system could have been used, the compact RIO provided a rugged, real time operating system with software programmable hardware (FPGA). The Compact RIO provides modular bus architecture and a variety of pluggable hardware modules to implement various serial and digital I/O ports for instrumentation.

The combination of the software development suite and compact RIO made it possible to proto-type and deploy a rugged real-time control system in a short lead time. A possible drawback using this technology is power consumption ( $30 \mathrm{w}$ continuous). In this application the power required for pumping was the significant power consumer (140w peak) with another $30 \mathrm{w}$ required to power the other systems. Power to the supply pumps to circulate water while the chambers were closed used another $30 \mathrm{w}$ averaged over a day.

\section{H. Software}

The graphical user interface (GUI) for the system was implemented using National Instruments LabView (C). LabView's graphical programming paradigm and rich set of software components enable rapid and flexible development of instrument drivers and user interfaces.

The GUI software components are displayed on a workstation on shore, using protocols based on TCP/IP for control and data telemetry from the controller electronics on the FOCE float; the network path is implemented with COTS $900 \mathrm{MHz}$ data radios

The CTDs were configured to log internally at 10 second intervals. The $\mathrm{pH}$ sensors were being polled at $1 \mathrm{~Hz}$. Instrument data records are logged locally on the RIO controllers as ASCII delimited text files. In this initial CP FOCE implementation, the data files are transferred to shore manually using FTP. When possible, instruments are configured to log internally as well to provide additional data safety.

\section{Control}

The $\mathrm{pH}$ control system aims to produce predicted future ocean acidification scenarios as an offset from the environment $\mathrm{pH}$ 
levels so that the $\mathrm{pH}$ enrichment in the experimental chambers is added to the diurnal variation in $\mathrm{pH}$ that occurs on the reef flat. At low tides the reef flat water stagnates and pools and the reef organisms' interaction with the pooling water changes the water chemistry and the $\mathrm{pH}$. Diurnal variations in reef flat $\mathrm{pH}$ can be as extreme as reaching $\mathrm{pH}$ levels over 8.2 during daytime low tides when photosynthesis by reef organisms photosynthesis fixes $\mathrm{CO}_{2}$ removing it from the water column, to as low as 7.9 during night time low tides when respiration by reef organisms increases the $\mathrm{CO}_{2}$ levels in the surrounding sea water. The $\mathrm{pH}$ offsets used experimentally are based on IPCC climate change scenarios [5]. The difference from the environment $\mathrm{pH}$ and the experimental offset determines the chamber $\mathrm{pH}$ set point and this set-point is compared to the measured $\mathrm{pH}$ in the chamber. This produces an error value which is processed by a simple Proportional and Integral (PI) control algorithm. The PI algorithm parameters was tuned to operate as best as possible over the measured range of flow rates. The PI controller produces a demand signal that is converted to pulse width modulation (PWM) to control the power going to one of the dosing pump motors. The flow direction and speed is determined by the Doppler velocity current meter measurement (Nortek, Vectrino), and the direction of the flow is used to determine the direction of dosing and therefore which dosing pump motor is turned on (Fig 9). In the December 2009 deployment, a single $\mathrm{pH}$ electrode was used to measure $\mathrm{pH}$ in the center of each chamber. One additional $\mathrm{pH}$ electrode was used to measure the environmental $\mathrm{pH}$ and was placed on the reef flat close to the experimental chambers.

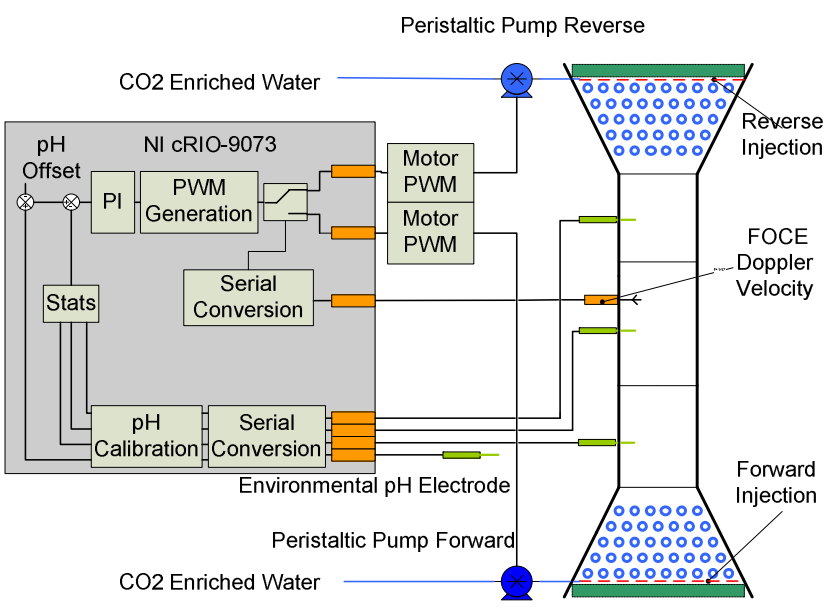

Figure 9: The CP-FOCE pH control system.

During the Heron Island CP FOCE experiment, two FOCE chambers were configured to maintain nominal offsets of -0.15 and $-0.30 \mathrm{pH}$ units from the adjacent environment. Input to the control loop for each chamber consisted of measured $\mathrm{pH}$ values averaged over 2 minutes, along with a measurement of current magnitude and direction along the chamber axis. The control system was successful in maintaining an offset below the environment as it traveled over nearly $1 \mathrm{pH}$ unit over 3 days (except during the periods when the chamber doors were closed for respirometry and calcification measurements, when no low $\mathrm{pH}$ water was being injected, Fig 9).

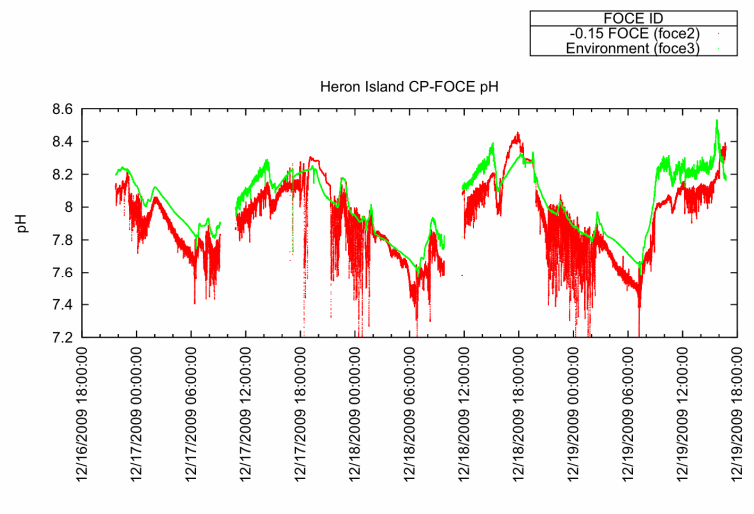

Date

Figure 10: CP-FOCE measured $\mathrm{pH}$ offset values during the December, 2009 Heron Island deployment.

The $\mathrm{pH}$ measurements were noisier than expected. Both the experiment lay out and environmental factors contributed to noise. An example of this is the distribution of pooled water. As the environmental $\mathrm{pH}$ sensor and $\mathrm{CP}$ FOCE chambers are between 1 and $10 \mathrm{~m}$ apart, location differences between the environmental $\mathrm{pH}$ sensor and the chambers mean each experience different valves of $\mathrm{pH}$ due to the pooling at low tide. From a CP-FOCE pH controller point of view, this induces noise into the environmental $\mathrm{pH}$ signal. Furthermore there are two types of delay in the chamber itself that make the $\mathrm{pH}$ control challenging. Transport delay occurs because the $\mathrm{CO}_{2}$ enriched water is dosed approximately $0.5 \mathrm{~m}$ to $1.1 \mathrm{~m}$ way from the sensors, and with average flow rates of $0.1 \mathrm{~m} / \mathrm{s}$ each $0.1 \mathrm{~m}$ represents a $1 \mathrm{~s}$ delay. The transport delay becomes significant at low flow rates to an extent that at slack tide the system becomes uncontrollable. The second delay in the chamber involves the mixing of the $\mathrm{CO}_{2}$ enriched water in the chambers. The mixing tabulators create small vortices which traps water until they dissipate. This delays water in time creating a mixing delay. Improvements in $\mathrm{pH}$ control, to more closely track the environmental $\mathrm{pH}$ are possible. A more advanced control algorithm that schedules the gain with water flow is a candidate but this will be considered in future work. Furthermore all future deployments will use at least $2 \mathrm{pH}$ 
sensors per chamber to reduce the delay in sensing transport changes.

\section{J. Flow Control Improvements}

To improve the operating range of the $\mathrm{pH}$ dosing, the flow conditioners' louvers are being replaced with flat PVC bladders. As the environmental water velocity increases, the PVC bladders are inflated with water to effectively reduce the inlet and outlet area of the flow conditioner. Hence this provides a means of reducing the flow through the chambers with minimal moving parts and with feed-back to the Doppler current velocity sensors (Nortek, Vectrino). To inflate the PVC bladders a bidirectional stepper motor/peristaltic pump controls the bladder water volume (Fig 11). Even though all practical efforts are employed to reduce the chamber turbulence, the raw Doppler current velocity data is passed through a median filter, in order to filter the noise created by residual turbulence within the chamber. A feedback loop is employed to control the stepper motor based on the maximum $\mathrm{pH}$ controllable water flow and the error in measured water flow.

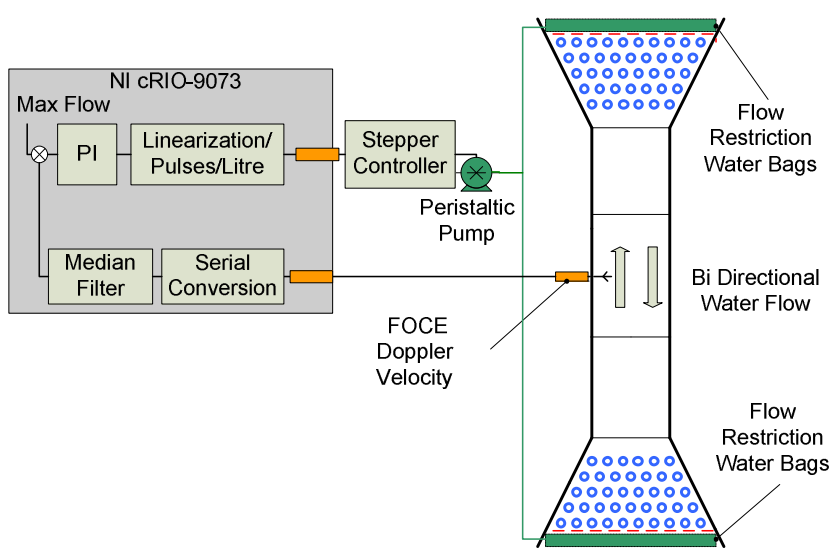

Figure 11: Flow control system in the next generation CP-FOCE system using flow restriction water bags and feed-back to the current velocity measurements.

\section{K. Deployment}

The doors in each chamber are typically closed for 1-2 hours during the day and night, and the water in the chambers sampled before and after the doors are closed. Sealing the sections allows the specimens inside them to change the chemistry of the water in a known volume for a known period of time so that rates of net production/respiration and net calcification/dissolution can be calculated by measuring the changes in oxygen and alkalinity, respectively. During the day net production rates can be calculated by measuring the increases in oxygen levels, while at night the respiration rate can be calculated based on the oxygen consumption. Net rates of calcification can be calculated by measuring the change in alkalinity, which will decrease with calcification, i.e. the uptake of $\mathrm{Ca}^{+2}$ ions in order to form calcium carbonate. The water in each chamber is typically sampled once every three hours throughout the experiments when the doors are open to monitor the carbonate chemistry. These water samples are analysed for Total Alkalinity (TA), Dissolved Inorganic Carbon (DIC), Dissolved Oxygen (DO), and nutrient levels in the laboratory.

\section{CONCLUSIONS}

Ocean acidification driven by increasing atmospheric $\mathrm{CO} 2$ represents a key threat to the coral reefs globally. Previous investigations have depended on studies in aquaria that are compromised by reduced ecological complexity and buffering capacity, and problems associated with containment. The CP-FOCE is the first coral reef in-situ ocean acidification system in which the impacts of predicted future $\mathrm{CO}_{2}$ concentrations can be studied on an intact coral reef ecosystem. The design of the CP-FOCE allows for wellcontrolled $\mathrm{pH}$ manipulation experiments using semi-enclosed chambers that can periodically be fully closed for respirometry and calcification measurements. The CP-FOCE system will likely prove to be an important new system for studying the impact of ocean acidification in coral reef environments.

\section{ACKNOWLEDGEMENTS}

Australian Government - 2009 ARC LIEF grant LE0989608 David and Lucile Packard Foundation

Sven Nylund (Nortek), Thom Maughan (MBARI), Heron Island Research Station Staff (UQ).

\section{REFERENCES}

[1] Hoegh-Guldberg, O., et al. (2007). Coral Reefs under Rapid Climate Change and Ocean Acidification. Science 318: 17371742 .

[2] Cao, L., and K. Caldeira (2008), Atmospheric $\mathrm{CO}_{2}$ stabilization and ocean acidification, Geophysical Research Letters, 35, L19609, doi:10.1029/2008GL035072.

[3] Silverman, J., Lazar, B., Cao, L., Caldeira, K. and Erez, J., 2009. Coral reefs may start dissolving when atmospheric CO2 doubles. Geophysical Research Letters, 36. doi:10.1029/2008GL036282 

analysis: results from the $\mathrm{C}^{14} \mathrm{MIP}$ model intercomparison. Journal of Climate 19: 3337-3353.

IPCC (2007). The Fourth Assessment Report: Working Group II: Climate Change 2007: Climate Change Impacts, Adaptation and Vulnerability.

Poloczanska, E. S., et al. (2007). Climate change and Australian marine life. Oceanography and Marine Biology: An Annual Review 45: 407-478.

Walther G, Post E, Convey P, et al. (2002) Ecological responses to recent climate change. Nature 416: 389-395.

[8] Brown, B. E. (1997). Coral bleaching: causes and consequences. Coral Reefs 16: S129-S138.

[12] Moy, A. D., W. R. Howard, S. G. Bray, and T. W. Trull. 2009. Reduced calcification in modern Southern Ocean planktonic foraminifera. Nature Geoscience 2: 276-280.

[13] Orr, J. C., V. J. Fabry, O. Aumont, L. Bopp, S. C. Doney, R. A Feely, A. Gnanadesikan, N. Gruber, A. Ishida, F. Joos, R. M. Key, K. Lindsay, E. Maier-Reimer, R. Matear, P. Monfray, A. Mouchet, R. G. Najjar, G.-K. Plattner, K. B. Rodgers, C. L. Sabine, J. L. Sarmiento, R. Schlitzer, R. D. Slater, I. J. Totterdell, M.-F. Weirig, Y. Yamanaka, and A. Yool. 2005. Anthropogenic ocean acidification over the twenty-first century and its impact on calcifying organisms. Nature 437: 681-686.

[14] Riebesell, U., I. Zondervan, B. Rost, P. D. Tortell, R. E. Zeebe, and F. M. M. Morel. 2000. Reduced calcification of marine plankton in response to increased atmospheric $\mathrm{CO}_{2}$. Nature 407: 364-367.

[15] Kleypas, J. A., et al. (1999). Geochemical consequences of increased atmospheric carbon dioxide on coral reefs. Science 284: $118-120$.

[16] Shirayama, Y. and Thornton, H. (2005). Effect of increased atmospheric $\mathrm{CO}_{2}$ on shallow water marine benthos. Journal of Geophysical Research 110: C09S08, doi:10.1029/2004JC002618.
Berge, J. A., et al. (2006). Effects of increased sea water concentrations of $\mathrm{CO}_{2}$ on growth of the bivalve Mytilus edulis. L. Chemosphere 62: 681-687.

Kleypas, J. A. and C. Langdon. (2007). Chapter 5: Coral Reefs and Changing Seawater Chemistry. Coral Reefs and Climate Change: Science and Management. J. Phinney, W. Skirving, J. Kleypas, O. Hoegh-Guldberg and A. E. Strong, Coastal and Estuarine Studies 61: 73-109.

Cooper, T. F., et al. (2008). Declining coral calcification in massive Porites in two nearshore regions of the northern Great Barrier Reef. Global Change Biology 14: 529-538.

Diaz-Pulido, G., L. J. McCook, A. W. D. Larkum, H. K. Lotze, J. A. Raven, B. Schaffelke, J. E. Smith, and R. S. Steneck. 2007. Vulnerability of macroalgae of the Great Barrier Reef to climate change, p. 153-192. In J. E. Johnson, P. A. Marshall (Ed), Climate change and the Great Barrier Reef. Great Barrier Reef Marine Park Authority \& Australian Greenhouse Office, Townsville.

Kuffner, I. B., A. J. Andersson, P. L. Jokiel, and K. S. Rodgers (2007). Decreased abundance of crustose coralline algae due to ocean acidification. Nature Geoscience online doi:10.1038/ngeo100: 1-4.

Hendrey, G.R., and B.A. Kimball (1994). The FACE Program. Agricultural and Forest Meteorology 70: 3-14.

Ainsworth E.A. and Long S.P. (2005). Tansley Review: What have we learned from 15 years of free-air $\mathrm{CO} 2$ enrichment (FACE)? A meta-analytic review of the responses of photosynthesis, canopy properties and plant production to rising CO2. New Phytologist 165, 351-372.

Kirkwood, W.J., et al. (2005). Engineering development of the Free Ocean CO2 Enrichment (FOCE) Experiment. MTS/IEEE Oceans 2005

Kirkwood, W.J., Peltzer, E.T., and P.G. Brewer. (2007). In Situ Ocean Acidification Environmental Observations: MBARI's Cabled Observatory Technology for Controlled Studies of Changing Ocean $\mathrm{pH}$. Underwater Technology and Workshop on Scientific Use of Submarine Cables and Related Technologies: 627-633.

Zeebe, R. and D. Wolf-Gladrow (2001). CO2 in seawater: equilibrium, kinetics, isotopes. Elsevier. Amsterdam. 346pp.

Brewer, P.G., E.T. Peltzer, P. Walz, I. Aya, K. Yamane, R. Kojima, Y. Nakajima, N. Nakayama, P. Haugan, T. Johannessen. (2005) Deep Ocean Experiments with fossil fuel carbon dioxide: creation and sensing of a controlled plume at 4 km depth. J. Mar. Res., 63, 9-33. 